\title{
Institutionalization of Contested Practices: A Case of Enterprise Architecture Implementation in a US State Government
}

\author{
Quang "Neo" Bui \\ Rochester Institute of Technology \\ qnbbbu@rit.edu
}

\author{
Matt Levy \\ Hawaii Pacific University \\ matthew.levy@gmail.com
}

\begin{abstract}
Information Systems (IS) practices are often 'institutionally contested' when introduced into organizations. They run counter to the status quo and disrupt organizational stability. Furthermore, they contravene the normative, regulatory, and culturalcognitive legitimacy in existing institutionalized processes. This research explores contested practices, examining the struggles and techniques IS organizations use to legitimize and institutionalize them. Using an institutional change and translation perspective, we investigate a case of Enterprise Architecture (EA) implementations in a US state government, highlighting the struggles in translating new practices to connect to potential users and in connecting new practices to existing norms, regulations, and cultural values. We elucidate two key techniques to overcome these struggles: inductive communication to make new practices relatable to users, and the deployment of experts to local contexts to facilitate knowledge transfer. The research shows how institutional change unfolds and informs practitioners of how to legitimize EA practices.
\end{abstract}

\section{Introduction}

Prior to becoming new institutions, new practices are often 'contested' when first introduced into organizations [38, 47, 33, 40]. They introduce new norms and values inconsistent with the prescriptive, evaluative, and obligatory dimensions of organizational life; they threaten the regulatory 'guardrails' of current institutions; and they propose new alternatives to the very frames from which social meaning has been constructed [40]. These new practices, which we refer to as 'institutionally

1 This research is supported by the National Science Foundation grant \#SES-0964909. contested organizational practices', or Contested Practices for short, are commonplace in the context of Information Systems (IS), particularly as organizations evolve their IS in response to environmental events, such as competitive threats, financial crises, or declining performance. When viewed through this lens, Contested Practices in IS are a source of tension. They create conflict in their respective organizations as they may lack cross-functional awareness [26], they may be difficult to integrate across business units [26], or they may face opposition from those whose beliefs are couched in existing institutions [38]. Thus, Contested Practices are 'illegitimate', as they contravene the existing normative, regulatory, and cultural-cognitive pillars of legitimacy [38], and are met with fierce opposition that can cause them, and the goals of those who espouse them, to face a slow death $[38,23,40,33$, 50].

To institutionalize Contested Practices - to make them socially and legitimately accepted [54, 51, 6]their proponents need to employ various techniques to construct new meanings [48] and encourage the enactment of those practices in organizational settings $[36,31]$. But what are the techniques that yield more efficient results? While researchers in other domains outside of IS have studied how organizations adopt and diffuse Contested Practices [38, 23], the struggles and enabling techniques associated with IS-specific Contested Practices are relatively unexplored. In this research we contend Contested Practices in the IS domain are quite different. Unlike managerial practices, IS-specific practices often involve technological systems (e.g., ERP, CRM), which are laden with institutional logics-the beliefs and norms about how best to conduct business activities [16]. Thus, by their very nature, new technologies and systems are institutionally contested, and so are the practices that employ them, and we contend IS research and practice are in need of a deeper, richer understanding of Contested Practices and how proponents of Contested Practices legitimize and institutionalize them. 
Table 1. Characteristics of contested practices

\begin{tabular}{|c|c|c|}
\hline Defy current norms and values & $\begin{array}{l}\text { Contested Practices challenge current institutional structures, } \\
\text { threatening the habituated and legitimized structures that } \\
\text { facilitate resource acquisition, stability, and enhanced } \\
\text { survival prospects. }\end{array}$ & $\begin{array}{l}{[6],[27],} \\
{[9],[18],} \\
{[41],[38],} \\
{[13],[47]}\end{array}$ \\
\hline $\begin{array}{l}\text { Cause shocks to the current } \\
\text { institutional environment } \\
\text { resulting in resistance from } \\
\text { institutional actors }\end{array}$ & $\begin{array}{l}\text { Contested Practices represent the forces that invoke shocks to } \\
\text { current institutional environments. They introduce change, } \\
\text { and, consequently, such shocks can be met with opposition } \\
\text { from institutional actors. }\end{array}$ & $\begin{array}{l}{[17],[18],} \\
{[41],[13],} \\
{[38],[40]}\end{array}$ \\
\hline $\begin{array}{l}\text { Leading organizational actors } \\
\text { facilitate and impose contested } \\
\text { practices on existing institutions }\end{array}$ & $\begin{array}{l}\text { Contested Practices originate from external environments, } \\
\text { facilitated by leading organizational actors, imposing } \\
\text { sociopolitical forces on current institutions, seeking to invoke } \\
\text { rapid and widespread change. }\end{array}$ & $\begin{array}{l}{[13],[22],} \\
{[38],[9],} \\
{[27],[46],} \\
{[34]}\end{array}$ \\
\hline $\begin{array}{l}\text { Transfer of knowledge is } \\
\text { challenging with contested } \\
\text { practices, requiring engagement } \\
\text { from institutional actors }\end{array}$ & $\begin{array}{l}\text { Contested Practices rely on techniques to impart external } \\
\text { knowledge and translate it into local settings. Lack of } \\
\text { engagement can weaken the knowledge-transfer process. }\end{array}$ & $\begin{array}{l}{[14],[12],} \\
{[32]}\end{array}$ \\
\hline
\end{tabular}

In this paper, we seek to elucidate deeper knowledge in response to the question of how Contested Practices become institutionalized in light of extant institutions [4]. To answer this question, we employ two related bodies of institutional theories: one from the institutional change perspective-specifically the literature on Contested Practices - and the other from the translation perspective to study how new practices are legitimized over time. These theoretical lenses are chosen because they allow us to understand the nature of Contested Practices and the necessary social changes to legitimize them over time. Using an interpretive approach, we present a case study of Enterprise Architecture (EA) implementation in a US state government. The findings suggest that EA implementation experiences two common difficulties: (1) a difficulty in translating EA value and practices, and (2) a difficulty in linking EA concepts to existing norms, values, and cultures. To remedy these difficulties, we report on two techniques EA proponents used to overcome these difficulties: (1) Inductive communication - EA proponents explained EA through metaphors and contextualized examples to make new concepts relatable to potential users, and (2) Consultative engagement - Enterprise Architects were deployed to local IT development projects in business units to help facilitate the enactment of EA principles. In applying both these techniques, these locally embedded architects acted as boundary spanners between the EA team and potential users to transfer knowledge, provide assistance to apply EA principles in local IT projects, and transfer local feedback back to the EA team.

This paper is organized as follows. Following Walsham [52], we first provide the theoretical foundation for our interpretive case study; specifically, we explicate the idea of Contested Practices and conceptualize institutionalization as a process of translation. Next, we provide a case detailing the implementation of Contested Practices in an EA organization. Lastly, we explore the theoretical contributions of this research and discuss how we can advance our understanding of contested IS practices.

\section{Theoretical foundation}

\subsection{Institutionally contested organizational practices}

Organizational practices represent the habituated actions, routines, and standard operating procedures that give organizations reliability. They represent the ways organizational functions are conducted over time given an organization's history, people, interests, and actions [21] and represent the 'genes' that emphasize an organization's taken-for-granted, subconscious, and tacit nature. In contrast, Contested Practices have yet to become habituated. They are liminal, existing at the threshold of transition, representing the forces that cajole institutional change, as they have yet to reflect the shared knowledge of an organization [21].

Contested Practices are born from the ideas of institutions and institutional change, as institutions represent the forces that suspend [28] and govern patterns of individual behavior $[6,27,10]$. Institutions are multidimensional, existing at a field-level as well as in any organizational environment where they are simultaneously embedded [38, 47]. However, they are not stagnant, but 'fluid', as institutions continuously change over time [18, 17, 41]. When institutions change, it is theorized to be the result of a 'jolt' or 'shock' to the current social structure [17, 18], and these shocks activate the process of change and 
consequently can be met with oppositional forces. Contested Practices represent the forces that cause these shocks, and, in this research, we explore the effects of these shocks at the organizational level and how they may be overcome.

In this research, we define four specific characteristics of Contested Practices that make their institutionalization a challenging endeavor. These characteristics are mentioned in prior research as key factors of the opposition toward Contested Practices: (1) Contested Practices contradict current institutional structures and defy existing social norms and values instilled in institutions and institutionalized processes $[38,13,22]$. (2) They introduce shocks to the organizational environment, and these shocks can be met with opposition from institutional actors as Contested Practices re-shape cognition around a new social order [41, 40]. (3) Contested Practices are external ideas introduced by leading organizational actors-change agents compelled to enact external practices in the ongoing search for legitimacy and efficiency [9, 46, 32]. (4) Contested Practices seek to impart and translate new knowledge into local settings, although the knowledge transfer is challenging due to resistance from institutional actors [32].

\subsection{Institutionalization as a translation process}

Institutionalization is a process that transforms social structures and behaviors to become taken for granted as a source of shared knowledge and common beliefs, considered 'socially defined', 'appropriate', and 'legitimate' [51, 6, 54]. Through the institutionalization process, new structures and behaviors are socially shaped, breaking down old habits, norms, and routines while introducing new rules and procedures $[41,18,19]$.

Institutionalization is theorized to occur at two different levels [5, 32, 53]. The first level is what we refer to in this research as a macro-level institutionalization process, which focuses on how social facts are constructed at the level of the institutional field-amongst a group of organizations and their impacts on members of that field [27]. The essential characteristic of this level is that it seeks to theorize how regularities occur in a broader institutional environment, how the institutionalization process unfolds, and how institutionalized structures and behaviors are transformed and transferred across organizations. Isomorphism is the key moniker used in macro-level institutionalization research that conceptualizes organizational structures and behaviors across the field [9], and the normative, mimetic, and coercive forces that exert pressure causing structural and behavioral convergence [10]. This view is often used to explore how external forces impact the diffusion of new structures, technologies, or practices $[18,50]$.

In contrast, the micro-level view considers institutionalization as a process through which new technologies and practices are socially constructed and legitimized, and become routines within an organization $[54,5]$. The context in which the institutionalization process unfolds is within an organization's boundaries; and organizational actors such as managers and rank-and-file employees contribute to the construction or deconstruction of institutions through their everyday activities. Compared to macro-level studies, the number of micro-level studies of the institutionalization process is much more modest [5, 36]. A few IS studies have examined the institutionalization process of a technology in organizations $[5,25]$, and these studies often take a socio-technical perspective and are interested in understanding how the dynamics between technology, organizational structures, organizational actors, and environments socially construct meanings and practices located within technology. While the socio-technical process is useful, it emphasizes sociotechnical changes throughout the institutionalization process and the evolution of technology over time [25]. It does not allow us to understand the struggles and enabling techniques that change agents need to employ over time to disrupt existing social orders, gain sociopolitical support, mobilize actions, and institutionalize Contested Practices. Especially for IS practices which often impact both technical structures and business processes, the oppositions can mount up significantly, and we need a deeper understanding of the role of change agents in the institutional change process [28].

In this research, we contribute to institutionalization research at the micro-level to examine how Contested Practices are institutionalized within organizations. Important to the idea of microlevel institutionalization is a translation process that occurs when micro-level organizations adopt macrolevel institutionalized concepts $[32,36]$. Through the translation process, abstract ideas in the external environments are interpreted, modified, and transformed into concrete and localized concepts that are easier to understand and apply [8]. The translation research originated from Scandinavian institutionalism [8], and, interestingly, these theories place keen emphasis on the struggles and enabling techniques associated with interpreting, enacting, and legitimizing new ideas and practices in local settings $[32,30]$.

In the context of our research, the translation perspective is a useful theoretical lens to study how new ideas taken from the external environments are transformed into organizational practices, and how 


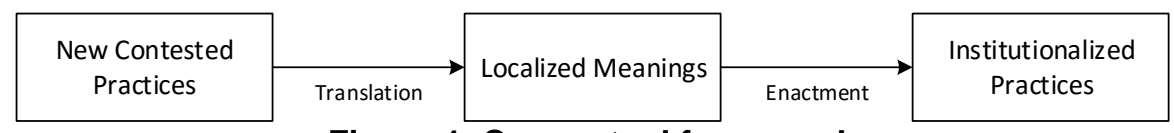

Fiqure 1. Conceptual framework

change agents are able to disrupt the established norms and habituated behaviors to enact new ideas and practices [36]. Additionally, the translation process pays greater attention to the social construction of meanings and values, something that the sociotechnical process lacks [32]. As new practices are translated into organizational settings, they are socially constructed and transformed by interactions of organizational actors to something new, and something modified for the particular needs of the local users [42, 8]. Thus, the translation perspective allows a deeper investigation of both symbolic and material changes that enact new practices. Recent IS studies have conceptualized the micro-level institutionalization process as a translation process in which abstract ideas taken from external environments are unpacked and reinterpreted into local meanings and practices [32].

In this research, we adopt the translation lens from Reay, et al. [36] to further our knowledge of institutionalization processes in IS contexts. In Reay et al. [36], three techniques have been identified as prominent in the translation process. The micro-level theorizing includes techniques such as framing and justifying the rationale for adopting new practices, and then proselytizing them to all potentially important audiences. The encouraging 'trying it' includes techniques that promote short-term engagements and de-habituate old practices such as co-locating professionals in interdisciplinary work arrangements or identifying non-financial incentives to motivate adoption. Lastly, facilitating collective meaningmaking involves techniques that allow habitualization of new practices as taken-for-granted social facts.

This research frames Contested Practices using the lens of translation (Figure 1). We posit that as new practices are introduced into organizations, they are institutionally contested because they defy existing norms and values, introduce shocks to the environment, present external ideas, and have difficulty in impart new knowledge. We theorize that, to institutionalize Contested Practices, proponents need to utilize different techniques to translate them into localized meanings and enact them in local settings.

\section{Research setting and analysis}

\subsection{EA as empirical setting}

EA is the organizing logic for business processes and IT infrastructure [37]. It is the process of translating business strategy into effective enterprise change - by creating, communicating, and improving the key principles and models that describe the enterprise's future implementation of technology [37, 2]. EA is considered a solution to some of the most frequently discussed challenges for IS management [24]. Many organizations, particularly large corporations and government agencies, envisage EA as a method to reduce IT complexity and enhance its effectiveness as it relates to organizational strategy through integration and standardization [37, 44]. Thus, EA is an important IS practice, as it sits right at the 'crux' of technology and social processes [24, 49, 43].

Despite the perceived importance of EA as an IS practice, proponents struggle to attract endorsement from organizational stakeholders, transfer know-how, and move beyond a technology-centric view [7, 49, 37]. Thus, EA struggles to become more than what is commonly realized in organizations [37, 49], and it becomes an ideal setting to study EA as a Contested Practice seeking legitimacy and institutionalization. Through the lens of Contested Practices, EA can be depicted in terms of its challenges in achieving its desired effects, and as a new practice that counters institutional norms. As EA seeks to alter existing IT infrastructure and business processes, it introduces new logics that counter existing work practices [39] and contravene existing norms, values, and culture.

\subsection{Case background}

In this research, we investigate the implementation of EA in a medium-size US state government. The state has more than 50,000 employees and an annual IT budget greater than $\$ 10$ million. State Enterprise had a federated IT structure where each agency acted as an autonomous business unit in providing public services such as health, public safety, and transportation. Its central IT organization provided common services such as central database and web services; however, state agencies largely had the autonomy to develop IT on their own. The central EA team, hereafter State EA, was located within the central IT organization.

The State EA was responsible for the development of a statewide EA framework (SEAF). The impetus for the framework was a 2003 initiative by a new CIO to reduce IT expenditures across the state. SEAF focused on IT standardization with Service-Oriented Architecture (SOA) envisaged as the IT architecture needed that could reduce development time and cut 
costs. However, while SEAF was seen as necessary by State EA and the new CIO, compliance with SEAF remained modest at best.

Changes occurred in 2008 when the state went through a statewide IT consolidation initiative and many agencies started to pay more attention to the cost-saving potential of EA. SEAF consequently gained traction and further compliance. At the time of our inquiry in 2011-2012, state agencies were more comfortable with SEAF, and a stream of new IT projects was being developed using SEAF guidelines.

\subsection{Data collection and analysis}

Seven one-hour semi-structured interviews were conducted with the state CIO, deputy CIO, EA director, agency CIOs, and enterprise architects. In addition, we collected archival data from reports, web pages, and other EA artifacts as secondary data to support the analysis. More than 80 documents $(2,000+$ pages) were collected and analyzed. Each of the interviews was transcribed and coded using the guidelines from George and Bennett [15]. Interviews served as the primary data source, while archival data were used as secondary data to support the analysis. Three different analysis techniques were used to analyze the data: First, archival data were coded to construct a historical account of EA implementation. Second, interview data were coded using theory-driven coding [15] to identify elements that are relevant to our purposes. We paid close attention to the concepts specified in the theory section. Particularly, struggles related to norms and values, to shocks; actions done by leading organizational actors; attempts to facilitate knowledge transfer [38]; and tactics used to construct meanings and encourage trying [36] (Table 2). Third, pattern matching and causal network analysis [29, 15] were used to relate struggles to specific tactics.

\section{Findings}

EA practices in the state were a Contested Practice in that (1) the practices defied the existing culture of each agency producing their own IT, (2) EA was opposed by the agencies, eschewing use of the SEAF, (3) EA was an external idea introduced by the CIO, and (4) the knowledge-transfer process of SEAF from State EA to state agencies was a challenging endeavor. Our enquiry suggests two common struggles that further contextualize the idea of translation in IS: (1) the difficulty State EA experienced in translating institutional field-level values to organizational practices, and (2) the difficulty in linking institutional field-level EA concepts to organizational norms, values, and cultures. We observed two common techniques used to cope with these struggles, which offer context to the Reay et al. framework: (1) the use of 'inductive' communication to better communicate EA value and practices, and (2) the use of consultative engagements through locally embedded architects to assist local IT projects.

\subsection{Struggles in EA institutionalization}

Translating $E A$ to organizational practices. Many of our interviewees consistently informed us of struggles related to the idea of translation. These struggles contained two emergent dimensions: (a) the struggle in communicating and educating the benefits of EA to state agencies engaging in IT development, and (2) the struggle in translating EA institutional field-level principles to specific organizational guidance for agencies to apply EA guidelines in their local settings. As one informant noted:

"I would say they [State EA] were probably trying to propagate that [EA] policy and the practice at [my agency] but I wouldn't say in those years, 2004 to 2008, I wouldn't say it was totally

Table 2: Coding Examples

\begin{tabular}{|l|l|}
\hline Coding concepts & Examples \\
\hline $\begin{array}{l}\text { Normative } \\
\text { struggles }\end{array}$ & $\begin{array}{l}\text { The initial response is that they always complain that 'oh, we don't have time', 'that's not } \\
\text { our business requirements', and 'we want to go with something like yesterday' }\end{array}$ \\
\hline $\begin{array}{l}\text { Shocks to the } \\
\text { organization }\end{array}$ & $\begin{array}{l}\text { I think that, I would say they were probably trying to propagate that policy and the practice } \\
\text { at the DIA but I wouldn't say in those years 2004 to 2008 I wouldn't say it was totally } \\
\text { successful }\end{array}$ \\
\hline $\begin{array}{l}\text { Imposing } \\
\text { contested } \\
\text { practices }\end{array}$ & $\begin{array}{l}\text { So different departments continue to have freedom to meet their specific business } \\
\text { requirements using a set of processes and technologies but they need to align to the SEAF. } \\
\text { So think of SEAF as an umbrella or an alignment mechanism. }\end{array}$ \\
\hline $\begin{array}{l}\text { Knowledge } \\
\text { transfer struggles }\end{array}$ & $\begin{array}{l}\text { Any one of these agencies, they haven't implemented a system in many years, so when they } \\
\text { get funding to implement a system, they have no internal experience or exposure with how to } \\
\text { implement the systems, the skillsets that are associated with it. }\end{array}$ \\
\hline
\end{tabular}


successful you know what I mean? I guess it's not a measure of success I think it's a measure of adoption and compliance, okay? With anything you need to educate people, you need to give them the tool to do their jobs. "- State Agency CIO (bold texts added)

Fortunately, in the state, many agencies were aware of the importance of EA. This could be attributed to the strong push for EA adoption in the US public sector, triggered by the 1996 Clinger-Cohen Act that mandated all federal agencies to have an 'IT Architecture' [1]. In addition, the state IT infrastructure was outdated and badly needed improvements, and agencies were eager for the potential EA could offer.

"If you look at State Enterprise, and you look at the systems exist within State Enterprise, if it's ever built or ever sold, we bought two of them, which meant there were a lot of applications that were very typical to integrate together but they all use different technologies and different codes, coding language and all of that, and it was very difficult to integrate things together because one was invented by one organization, the other by another."-State EA Director

However, while agencies did not need much convincing of the potential benefits of EA, they struggled with the application of EA principles in their own practices. This was the case because most agencies lacked the funding and expertise to do so.

"Any one of these agencies, they haven't implemented a system in many years, so when they get funding to implement a system, they have no internal experience or exposure with how to implement the systems, the skillsets that are associated with it. "-State CTO

Furthermore, the struggle for translation continued because, like any IS practice, EA contains a complex blend of concepts and IT artifacts [35, 45]. Subsequently, EA proponents need to communicate the EA concepts to potential users to showcase their value, but they also need to translate how those concepts are applied in actual processes and tangible artifacts that deliver benefits to users.

“... there're really two sides to an Enterprise Architecture. There's conceptual side, which is the idea that you're trying to achieve, like your goals and how you going to do that ... It works on the papers, you know, or it looks great now on the Internet, right? But it stops. It's all meaningless unless someone physically and basically can do it...Before that happens, you surely have nothing more than a really good set of ideas. "-State EA Director

In sum, the translation process from EA as a fieldlevel concept encountered significant difficulties in getting agencies to understand the value of EA as a potential practice to streamline IT operations and IT expenditures and to replace the unsustainable existing practices. Furthermore, this was exacerbated by the fact that EA represents a more holistic IS practice, encompassing a complex blend of concepts and IT artifacts that delineate new organizational processes and IT standards.

Difficulty in linking EA to existing norms, regulations, and cultures. Contested Practices contravene existing normative, regulatory, and cultural-cognitive legitimacy of existing institutions. This was evident in our case where EA violated the taken-for-granted beliefs, represented a deviation from established norms, and conflicted with cultural values. State EA faced a difficult time in making EA part of the organizational practices.

"The initial response is that they always complain that 'oh, we don't have time', 'that's not our business requirements', and 'we want to go with something like yesterday'. All those stuffs. "-State Agency Architect

"So, it's not that people is resistant to change, but everybody is very busy. They're all doing their things. They have the missions from their own organization that they have to meet ... You need to negotiate with folks that they need to participate and get the right level of sponsorship, particularly from the bottom-up efforts. Sometimes it's difficult to get people to cooperate."-State EA Architect

Moreover, State EA experienced strong opposition when it contravened existing cultural values regarding agency autonomy. The state had a federated IT structure that provided local autonomy to agencies in IT decisions, and because EA was centered around integration and standardization [37], it threatened the existing culture, making users uncomfortable with State EA's proposed changes. This forced the hand of State EA, reducing their focus to technical standards and ignoring standards regulating business processes.

"...each of those [agencies] is starting to pursue their own Business Application Architecture, Information Architecture, specific to their domains 
and their specific line of business...We're [State EA] not directly related to any one line of business. We're less likely to influence the business applications with Business Architecture or even some in Application Architecture. "-State EA Architect

These struggles emerged from a lack of clear understanding about the roles and meanings of EA as well as a lack of knowledge about how to apply EA in local practices. EA ideas were embraced by state leadership seeking greater IT standardization and lower IT costs. Compliance with EA principles was mandated but there were limited actions to educate and assist state agencies. EA compliance was left to the interpretation of agencies that lacked not only expertise but also funding to implement new technologies. Not surprisingly, SEAF was largely disregarded and met with weak compliance in early phases (2003-2008). In some agencies, there was only ceremonial conformity [27] where compliance was only effective on paper.

\subsection{Techniques to institutionalize EA practices}

Use of inductive communication to better communicate $\boldsymbol{E A}$ value and practices. To address the struggles of translating EA value and practices, State EA employed an inductive communication style that made EA practices relatable to prospective users. Specifically, state architects used metaphors, explaining EA value and implications in the users' local settings, and targeted specific concerns important to the users. This technique allowed users to make sense of EA practices and their impacts on day-to-day activities. It also turned abstract EA concepts taken from the institutional-level field into concrete examples, allowing business units to relate EA to underlying strategic issues. For example, when explaining the concept of a service registry and repository (i.e., Universal Description Discovery and Integration [UDDI]) to the Health and Human Services Agency, SEAF was compared to a catalog in a library that allowed patrons to locate books. Simple metaphors worked best with leadership, while metaphors that were more technical resonated with IT developers. Over time, the metaphors became more applicable as the enterprise architects learned more about the agency to apply that knowledge in espousing SEAF.

"We often use concrete examples of saying that their current systems are either broken or have very limiting features or features that should be extended ...So we focus on things specific to their business that would have measureable impact if they would make them: design in smaller bits and more loosely coupled with the eco-systems around them so that they could change more rapidly with the changing business conditions and business requirements. "-State EA Architect

To legitimize EA practices, the focus was adjusted toward helping users solve their problems through EA principles rather than checking for EA compliance. The communication took a softer tone and a helping attitude. State EA realized that local autonomy must be respected, and changing organizational culture would take time and constant communication. The architects consistently explained EA benefits and practices using specific examples that were found in local settings, or using specific issues that were important to the users.

"So I would categorize my involvement as not going to a state agency and say "if you want to implement the SEAF, I would help you to implement the Enterprise Architecture concept." I'd rather "here I would help you in the overall process of modernization, and help ensure that it would be consistent with the direction of the State EA." So the driver for that effort is a little bit different."-State EA Architect

Use of consultative engagements to assist local IT projects. While inductive communication allowed State EA to break down skepticism and reduce confusion and opposition, it only made EA concepts more relatable and understandable. Potential users still have a 'knowledge barrier' [3] — how to take those EA principles and apply them in local settings in ways that would not significantly disrupt existing norms, regulations, and cultures. Thus, EA teams must transfer knowledge to local IT teams so they would know how to incorporate EA principles in their daily activities.

To accomplish this, State EA deployed enterprise architects into local settings, giving them consultative roles, and assisting IT developers in applying EA principles to local IT projects. The enterprise architects use what we term a consultative engagement styleproviding guidance and assistance to local IT projects and teaching IT developers how to follow EA principles. They effectively acted as embedded change agents [2] that operated at the boundaries of the central and local IT teams. They facilitated interactions, enabling knowledge sharing and allowing the exchange of cultural values between two distinct organizationsthe central IS organization and the local IS team.

"Now that we have the standard, how can EA help you [agencies] either in selecting products that are needed in the standards or how we can help put the pieces together that integrate with the 
existing pieces that you want to retain...we often help write the RFP (Request for Proposal) to procure a new component or new system...And I also participate in the selection committee to review all those responses. So it is part of my review process with them, you know, it's a little bit of education [and] transfer of knowledge."-State EA Architect Embedded in an Agency

Using locally embedded architects helped legitimize EA practices, making them fit better with existing normative beliefs, regulatory procedures, and cultural values. Business units could retain their autonomy and only took advice from architects when they felt they needed help to improve the process. This approach shifted EA's responsibility from a 'sales' job to an 'advisory' job-something better appreciated by their users. More importantly, business units grew accustomed to using EA principles over time, and EA practices were slowly institutionalized. At the time of our inquiry, in the state, there were large state-wide collaborative health IT projects made possible by EA principles (e.g., service-oriented architectures); and state agencies were actively reaching out to request that architects be in their new projects.

"So I've actually been loaned to the agency for two years, working with them. And right now they do consider it if I've been taken away, I think they still request for an architect to be part of the project."-State EA Architect Embedded in an Agency

"...we do have an architect aside to review most or all of the projects as far as I know. But in addition to have an architect aside, often time, even if we don't have an architect, the agency CIOs will come to our CTO and ask specifically for somebody for short-term loan, you know, maybe a one or two days meeting or design lesson. It could be a couple of weeks, so it really varies. They often come to us and ask for a person to participate if we have time."-State EA Architect Embedded in an Agency

In sum, State EA took actions to better translate EA values and practices to concrete examples whose meanings are understood by the agencies. The act of embedding architects into agency IT projects assisted in linking EA field-level practices to organizational norms, regulations, and cultural values. It ultimately facilitated a new form of autonomy; that is, agencies began implementing EA without the enterprise architects involved. At the time of our interviews, the enterprise architects expressed hope that once 'embedding' was no longer common practice, SEAF would still be ingrained in the agencies' routines.

\section{Discussion}

Contested Practices are those that contravene the normative, regulatory, and cultural-cognitive pillars of legitimacy [38, 40]. In this research, we depict two challenges in introducing EA as an organizational practice: 1) the difficulty in translating institutional field-level EA concepts to organizational practices, and 2) the difficulty in linking EA concepts to existing norms, values, and cultures. At State EA, tensions emerged between state agencies and the EA teams, particularly because institutional actors - state agencies - are not easily able to discern benefits over current institutional forms, and furthermore, they are unaware of how new practices could be applied in their current institutional environment. Two tactics emerged showing how the team overcomes the aforementioned challenges: 1) the use of inductive communication to better communicate EA values and practices, and 2) the use of consultative engagement through locally embedded architects to assist local IT projects.

\subsection{Two problems with contested practices}

Our case illustrates (1) the usefulness in viewing the institutionalization of IS practices as Contested Practices and (2) the usefulness in viewing institutionalization through a translation lens. When viewing common IS practices through this lens, issues arise that exemplify why implementing and enacting IS practices have experienced significant challenges [24]. Much of the prevailing view on how new practices can gain legitimacy during the institutionalization process utilizes a macro-level view and focuses on change agents with their use of discursive strategies to frame and motivate institutional actors to take up new practices [48, 11, 20]. While such approaches are helpful in addressing educational aspects, they fail to address the knowledge transfer struggles endemic to institutionalization efforts. Our findings illustrate the importance of not only translating new practices in concepts that are related to the users in order to educate them, but also in providing the knowledge that allows the users to apply the new practices in their works.

These struggles highlight the two inherent problems in institutionalizing a Contested Practice. Because IS practices consist of conceptual and material components $[35,45]$, their proponents must 1) translate abstract concepts of new concepts into local meanings so users can relate to them, and 2) explicate detailed applications of new concepts and practices in local settings so users can know how to use them. These two 
problems are related. As our case illustrates, if change agents focus primarily on the first problem, and simply produce elaborate white papers and diagrams as means to explain new concepts, they risk being perceived as 'paper tigers' (a term heard more than once during our interviews) that users see no value in. In contrast, if change agents emphasize the second problem, detailing the applications of new concepts and practices in a meticulous way, they risk being perceived as 'nosy policemen' (another frequently heard term) that users avoid, or worse, fight back against.

These two related problems call for attention from IS researchers to identify techniques that allow change agents to address both problems. In our case, EA proponents were able to use inductive communication and locally embedded change agents to better connect to their potential users while still respecting their autonomy. Other studies have pointed out similar techniques, such as the use of collective forums with diverse representatives to reach consensus and build momentum [7, 2, 37]. Future research can reveal other techniques in different settings or practices.

In sum, we have depicted throughout the paper the use of Contested Practices and the translation process as useful analytical lenses to study the institutionalization of IS practices. We posit that the idea of Contested Practices in IS deserves greater attention, as both IS researchers and practitioners seek to understand the alignment between old and new practices in pursuit of their implementation.

\subsection{Conclusions, Limitations, and Future Research}

This research is not without limitation. It builds upon a single case, and thus, findings can only be generalized to theory rather than a broad population. Future research can explore Contested Practices in other sectors such as private firms or non-profit organizations to understand how they are legitimized and institutionalized, and perhaps explicate generalizations to populations based on their findings.

In addition, there are many more challenges that IS practices face that are not illustrated in this research, such as those that are technological. Therefore, future research can provide a rich context in identifying these challenges and offering practitioners ways to overcome them. For example, the issue of how technical standards and infrastructure dictate how Contested Practices are institutionalized.

\section{References}

[1] A Practice Guide to Federal Enterprise Architecture, Chief Information Officer Council, 2001.
[2] F. Ahlemann, E. Stettiner, M. Messerschmidt and C. Legner, Strategic Enterprise Architecture Management: Challenges, Best Practices, and Future Developments, Springer, New York, 2012.

[3] P. Attewell, "Technology Diffusion and Organizational Learning: The Case of Business Computing", Organization Science, 3 (1992), pp. 1-19.

[4] C. Avgerou, "IT and Organizational Change: An Institutionalist Perspective", Information Technology \& People, 13 (2000), pp. 234-262.

[5] J. Baptista, "Institutionalisation as a Process Of Interplay Between Technology And Its Organisational Context Of Use", Journal of Information Technology, 24 (2009), pp. 305-319.

[6] P. L. Berger and T. Luckmann, The Social Construction of Reality: A Treatise in the Sociology of Knowledge, Doubleday, Garden City, NY, 1967.

[7] W. F. Boh and D. Yellin, "Using Enterprise Architecture Standards in Managing Information Technology", Journal of Management Information Systems, 23 (2007), pp. 163-207.

[8] B. Czarniawska and G. Sevón, Translating Organizational Change, New York, Walter de Gruyter, 1996.

[9] P. J. DiMaggio and W. W. Powell, "The Iron Cage Revisited: Institutional Isomorphism and Collective Rationality in Organizational Fields", American Sociological Review, 48 (1983), pp. 147-160.

[10] P. J. DiMaggio and W. W. Powell, The New Institutionalism in Organizational Analysis, University of Chicago Press, Chicago, IL, 1991.

[11] N. Erkama and E. Vaara, "Struggles over Legitimacy in Global Organizational Restructuring: A Rhetorical Perspective on Legitimation Strategies and Dynamics in a Shutdown Case", Organization Studies, 31 (2010), pp. 813839.

[12] C. M. Fiol, "Consensus, Diversity, and Learning in Organizations", Organization Science, 5 (1994), pp. 403-420.

[13] P. C. Fiss and E. J. Zajac, "The Diffusion of Ideas over Contested Terrain: The (Non)adoption of a Shareholder Value Orientation among German Firms", Administrative Science Quarterly, 49 (2004), pp. 501-534.

[14] P. C. Fiss and E. J. Zajac, "The Symbolic Management of Strategic Change: Sensegiving Via Framing and Decoupling", Academy of Management Journal, 49 (2006), pp. 1173-1193.

[15] A. L. George and A. Bennett, Case Studies and Theory Development in the Social Sciences, MIT Press, Cambridge, MA, 2005.

[16] S. Gosain, "Enterprise Information Systems As Objects And Carriers Of Institutional Forces: The New Iron Cage?", Journal of the Association for Information Systems, 5 (2004), pp. 151-182.

[17] R. Greenwood and C. R. Hinings, "Understanding Radical Organizational Change: Bringing Together the Old and the New Institutionalism", The Academy of Management Review, 21 (1996), pp. 1022-1054.

[18] R. Greenwood, R. Suddaby and C. R. Hinings, "Theorizing Change: The Role of Professional Associations in the Transformation of Institutionalized Fields", Academy of Management Journal, 45 (2002), pp. 58-80.

[19] C. R. Hinings, R. Greenwood, T. Reay and R. Suddaby, "Dynamics of Change in Organizational Fields", in M. S. 
Poole and A. H. Van de Ven, eds., Handbook of Organizational Change and Innovation, Oxford University Press, New York, NY, 2004.

[20] E. Kaganer, S. D. Pawlowski and S. Wiley-Patton, "Building Legitimacy for IT Innovations: The Case of Computerized Physician Order Entery Systems", Journal of the Association for Information Systems, 11 (2010), pp. 133.

[21] T. Kostova, "Transnational Transfer of Strategic Organizational Practices: A Contextual Perspective", Academy of Management Review, 24 (1999), pp. 308-324.

[22] M. S. Kraatz and J. H. Moore, "Executive Migration and Institutional Change", Academy of Management Journal, 45 (2002), pp. 120-143.

[23] M. S. Kraatz and E. J. Zajac, "Exploring the Limits of the New Institutionalism: The Causes and Consequences of Illegitimate Organizational Change", American Sociological Review, 61 (1996), pp. 812-836.

[24] J. Luftman, H. S. Zadeh, B. Derksen, M. Santana, E. H. Rigoni and Z. D. Huang, "Key Information Technology and Management Issues 2011-2012: An International Study", Journal of Information Technology, 27 (2012), pp. 198-212.

[25] K. Lyytinen, M. Newman and A.-R. A. Al-Muharfi, "Institutionalizing Enterprise Resource Planning in the Saudi Steel Industry: A Punctuated Socio-technical Analysis", Journal of Information Technology, 24 (2009), pp. 286-304.

[26] R. Marciniak, R. E.L. Amrani, F. Rowe and F. Adam, "Does ERP Integration Foster Cross-Functional Awareness? Challenging Conventional Wisdom for SMEs and Large French Firms", Business Process Management Journal, 20 (2014), pp. 865-886.

[27] J. W. Meyer and B. Rowan, "Institutionalized Organizations: Formal Structure as Myth and Ceremony", The American Journal of Sociology, 83 (1977), pp. 340-363.

[28] M. Mignerat and S. Rivard, "Positioning the Institutional Perspective in Information Systems Research", Journal of Information Technology, 24 (2009), pp. 369-391.

[29] M. B. Miles and A. M. Huberman, Qualitative Data Analysis, SAGE Publications, Thousand Oaks, CA, 1994.

[30] T. Morris and Z. Lancaster, "Translating Management Ideas", Organization Studies, 27 (2006), pp. 207-233.

[31] S. Newell, J. A. Swan and R. D. Galliers, "A Knowledge-Focused Perspective on the Diffusion and Adoption of Complex Information Technologies: The BPR Example", Information Systems Journal, 10 (2000), pp. 239259.

[32] J. A. Nielsen, L. Mathiassen and S. Newell, "Theorization and Translation in Information Technology Institutionalization: Evidence from Danish Home Care", MIS Quarterly, 37 (2013), pp. 165-186.

[33] D. C. North, Institutions, Institutional Change and Economic Performance, Cambridge University Press, Cambridge, MA, 1990.

[34] C. Oliver, "Strategic Responses to Institutional Processes", Academy of Management Review, 16 (1991), pp. 145-179.

[35] W. J. Orlikowski, "The Duality of Technology: Rethinking the Concept of Technology in Organizations", Organization Science, 3 (1992), pp. 398-427.

[36] T. Reay, S. Chreim, K. Golden-Biddle, E. Goodrick, B. E. B. Williams, A. Casebeer, A. Pablo and C. R. B. Hinings,
"Transforming New Ideas into Practice: An Activity Based Perspective on the Institutionalization of Practices", Journal of Management Studies, 50 (2013), pp. 963-990.

[37] J. W. Ross, P. Weill and D. C. Robertson, Enterprise Architecture as Strategy: Creating a Foundation for Business Execution, Harvard Business School Press, Boston, MA, 2006.

[38] W. G. Sanders and A. Tuschke, "The Adoption of Institutionally Contested Organizational Practices: The Emergence of Stock Option Pay in Germany", Academy of Management Journal, 50 (2007), pp. 33-56.

[39] J. Schekkerman, How to Survive in the Jungle of Enterprise Architecture Frameworks, Trafford Publishing, Victoria, Canada, 2004.

[40] W. R. Scott, Institutions and Organizations, Sage, Thousand Oaks, CA, 2001.

[41] M.-G. Seo and W. E. D. Creed, "Institutional Contradictions, Praxis, and Institutional Change: A Dialectical Perspective", Academy of Management Review, 27 (2002), pp. 222-247.

[42] G. Sevón, "Organizational Immitation in Identity Transformation", in B. Czarniawska and G. Sevón, eds., Translating Organizational Change, New York, Walter de Gruyter, 1996.

[43] D. Simon, K. Fischbach and D. Schoder, "An Exploration of Enterprise Architecture Research", Communications of the Association for Information Systems, 32 (2013), pp. 1-72.

[44] H. A. Smith, R. T. Watson and P. Sullivan, "Delivering An Effective Enterprise Architecture At Chubb Insurance", MIS Quarterly Executive, 11 (2012), pp. 75-82.

[45] D. Strang and J. W. Meyer, "Institutional Conditions for Diffusion", Theory and Society, 22 (1993), pp. 487-511.

[46] M. C. Suchman, "Managing Legitimacy: Strategic and Institutional Approaches", The Academy of Management Review, 20 (1995), pp. 571-610.

[47] R. Suddaby, "Challenges for Institutional Theory", Journal of Management Inquiry, 19 (2010), pp. 14-20.

[48] R. Suddaby and R. Greenwood, "Rhetorical Strategies of Legitimacy", Administrative Science Quarterly, 50 (2005), pp. 35-67.

[49] T. Tamm, P. B. Seddon, G. Shanks and P. Reynolds, "How Does Enterprise Architecture Add Value to Organisations?", Communications of the Association for Information Systems, 28 (2011), pp. 141-168.

[50] P. S. Tolbert and L. G. Zucker, "Institutional Sources of Change in the Formal Structures of Organizations: The Diffusion of Civil Service Reform, 1880-1935", Administrative Science Quarterly, 28 (1983), pp. 22-39.

[51] P. S. Tolbert and L. G. Zucker, "The Institutionalization of Institutional Theory", in S. R. Clegg, C. Hardy and W. R. Nord, eds., Handbook of Organization Studies, Sage Publication, Inc., Thousand Oaks, CA, 1996, pp. 175-190.

[52] G. Walsham, "Doing Interpretive Research", European Journal of Information Systems, 15 (2006), pp. 320-330.

[53] L. G. Zucker, "Institutional Theories of Organization", Annual Review of Sociology, 13 (1987), pp. 443-464.

[54] L. G. Zucker, "The Role of Institutionalization in Cultural Persistence", American Sociological Review, 42 (1977), pp. 726-743. 